\title{
Effect of Mobilization with Movement versus Diclofenac Phonophoresis on Shoulder Adhesive Capsulitis
}

\author{
MAHA F. SAYED EL SAWABEY, M.Sc.*; WADIDA H. ELSAYED, Ph.D.*; \\ ASHRAF N. MOHARRAM, M.D.** and DALIA M. MOSAAD, Ph.D.* \\ The Department of Physical Therapy, Basic Sciences, Faculty of Physical Therapy* and \\ The Department of Orthopedic Surgery, Faculty of Medicine**, Cairo University, Egypt
}

\begin{abstract}
Background: Adhesive capsulitis is a common cause of shoulder pain and disability. It is characterized by spontaneous onset of shoulder pain accompanied by progressive limitation of both active and passive glenohumeral movement. Mobilization with Movement (MWM) and diclofenac phonophoresis are of the most effective management techniques of adhesive capsulitis in decreasing pain and improving range of motion. After the application of MWM the pain is reduced. Also Ultrasonic relieves pain and stiffness. Adding NSAID gives additional pain relief.
\end{abstract}

Aim of Study: To compare the effect of MWM technique versus diclofenac phonophoresis on pain intensity level and shoulder range of motion in patients with shoulder adhesive capsulitis.

Design of Study: Randomized control trial, pre-test posttest design was used.

Method: Thirty-six patients were recruited according to power analysis, were divided randomly into three groups. All groups received conventional physical therapy program for four weeks Group (A): 14 patients received conventional physical therapy only; while in Group (B): Diclofenac phonophoresis was added three times per week for 11 patients, and in Group (C): MWM technique was added twice per week for 11 patients. Numerical pain rating scale was used to measure the pain intensity level and saunders digital inclinometer was used to measure the shoulder range of motion.

Results: There was statistical significant difference within the three groups, in decreasing pain intensity score and improving shoulder range of motion. Between groups; there were significant difference in decreasing pain intensity score and increasing shoulder flexion, internal and external rotation. Internal and external rotation were significantly improved favoring MWM in comparison to phonophoresis group, $p<0.05$.

Conclusion: The study concluded that both diaclofenac phonophoresis combined with conventional physical therapy program and MWM had decreased the patient's pain severity and increased the shoulder ROM. But, MWM technique

Correspondence to: Dr. Maha F. Sayed El-Sawabey, The Department of Physical Therapy, Basic Sciences, Faculty of Physical Therapy, Cairo University, Egypt combined with conventional physical therapy program had the superiority in improving the shoulder ROM.

Key Words: Adhesive capsulitis - Phonophoresis - Mobilization with movement - Digital inclinometer.

\section{Introduction}

FROZEN shoulder is a musculoskeletal disorder in which the capsule of joint, surrounding connective tissue becomes stiff, inflamed and shortened; it is also called Adhesive Capsulitis (AC) [1,2] . It grows gradually from restriction of shoulder range of movements to sever stiffness and chronic pain $[1,2]$. Adhesive capsulitis is an idiopathic disease with two principal characteristics: Pain and contracture. Shoulder pain is progressive and initially felt mostly at night or when the shoulder is moved close to the end of its Range of Motion (ROM). It can be caused by certain combined movements of the shoulder, such as abduction and external rotation (e.g, grooming one's hair) or extension and internal rotation (e.g, reaching for a back pocket). Contracture the second principal characteristic is progressive loss of passive ROM (PROM) and active ROM (AROM) of the glenohumeral joint in a capsular pattern [3] . Frozen shoulder affects mainly individuals 40-65 years of age with a female predominance [4]. There are three stages of AC, each lasting 4-6 months [5]. Stage one is the painful or freezing phase. During this stage, the pain is severe by any attempts at movement; it lasts a few weeks or months. Stage two is the adhesive or stiffening phase and generally lasts 4 to 12 months. Pain is usually minimal during this phase. The third stage of the syndrome is the resolution or thawing phase and may last 5 to 26 months. During this time the pain eases, and motion slowly improves [6]. 
The mobilization with movement technique is done with both therapist and patient participation. Passive glide is done by physiotherapist at peripheral joint meanwhile patient performs pain free physiologic movement [7]. MWM developed by Brian Mulligan that treats joint dysfunction [8] The hallmark of MWM technique is that pain should be decreased and shoulder function should be improved after the application of technique $[9,10]$.

Phonophoresis is also known as sonophoresis or ultrasonophoresis. This implies the movement of drugs through intact skin into the subcutaneous tissues under the influence of ultrasound. Many drugs are absorbed through the skin very slowly, using ultrasound $1 \mathrm{MHz}$ increases the absorbtion [11]. Phonophoresis is common in treatment of musculoskeletal diseases including adhesive capsulitis of shoulder [12].

The purpose of this study was to compare the effect of mobilization with movement technique versus diclofenac phonophoresis on pain intensity level and shoulder range of motion in patients with shoulder adhesive capsulitis.

\section{Subjects, Material and Methods}

The study was designed as a prospective, randomized, single-blind, pre-post-test, controlled trial. The independent variables were MWM technique and diclophenac phonophoresis. The dependent variables were pain intensity level and ROM of shoulder joint. A convenient sample of 36 participants were recruited (according to power analysis) from Ministry of Health Hospital (Fifth Settlement Medical Center), Educational Hospitals (Al-Kasr El-Aini Hospital) and, Outpatient Clinic of Faculty of Physical Therapy, Cairo, Egypt, from June 2017 to December 2017.

They were enrolled and assessed for their eligibility to participate in the study. They were randomly assigned into three groups (A, B \& C) by a blinded research assistant assisted in opening sealed envelopes. The study was registered by The Pan African Clinical Trials Registry (PACTR) (PACTR201808561062521). Ethical approval was obtained from the institutional review board at Faculty of Physical Therapy, Cairo University, Egypt, before study commencement. The study followed the Guidelines of Declaration of Helsinki on conduction of human research.

An informed consent was obtained from all participants before the beginning of the study.
Inclusion criteria: Participants were included if they were diagnosed as second stage adhesive capsulitis (Frozen shoulder) referred by physicians. Diagnosed by physicians with Magnetic Resonance Imaging (MRI). The severity of pain on numerical pain rating scale was higher than three out of ten, pain aggravated by movements, patients were suffering from pain and limitation in the motion for more than 3 months, patients with AROM/ PROM less than or equal to 90 degrees at external rotation, abduction, internal rotation and flexion. The Body Mass Index (BMI) of participants doesn't exceed $34 \mathrm{~kg} / \mathrm{m}^{2}[\mathbf{1 3}]$

Exclusion criteria: Participants were excluded according to the following criteria [14] patients having any intra articular injection in the glenohumeral joint during last three months, patients with musculoskeletal disorder (any type of fracture), any history of surgery on that shoulder and patients with tendon calcification, patients with cervical rib, rotator cuff tear patients, all the patients with cervical and thoracic spine dysfunctions are first ruled out and patients with any neurological conditions.

Participants were randomly assigned into three groups. All groups received conventional physical therapy program for four weeks [15]. Group (A) 14 patients received conventional physical therapy only for four weeks, and in Group (B): Diaclofenac phonophoresis was added three times per week for 11 patients, as pulsed U.S $1 \mathrm{MHz} 1.5 \mathrm{~W} / \mathrm{cm}^{2}$ for 10 minutes with using NSAND (voltaren gel) [16,17] Group (C) MWM technique was added twice per week for 11 patients [14]

\section{Procedures:}

All participants were evaluated before applying the program and immediately after the four weeks program. Measurement procedures the pain intensity level measured by Numerical Pain Rating Scale (NPRS). The patient was asked to place mark at his/her level of pain at sheet of NPRS. NPRS is a valid and reliable measure of chronic pain intensity [18]. Shoulder range of motion (flexion, abduction, internal and external rotation) by Saunders digital inclinometer. Patient was in supine position for measuring shoulder flexion in both active and passive ROM. Mark the acromion process as the landmark for measuring, below the acromion by two fingers put the digital inclinometer on the anterior aspect of the humerus while the digital inclinometer faces the therapist and the therapist standing at the side of the examined shoulder of the patient while the arm at the patient side. Set the digital inclinometer to zero then hold. The 
patient moved the arm forward for shoulder flexion then pressed hold to take the reading.

For measuring shoulder abduction, patient was in supine position for measuring shoulder abduction in both active and passive ROM. Mark the acromion process as the landmark for measuring, below the acromion by two fingers put the digital inclinometer on the lateral aspect of the humerus, while the digital inclinometer faced the therapist and the therapist standing facing to the examined shoulder. Set the digital inclinometer to zero then hold. The patient moved the arm sideway away from the body for measuring shoulder abduction then pressed hold to take the reading.

For measuring shoulder internal and external rotation, patient was in supine position for measuring active and passive ranges. The patient abducted the arm 90 degrees with flexion elbow and forearm supinated. The therapist stood beside the measured shoulder between the patient's shoulder and head. Therapist applied the digital inclinometer on the patient's forearm while it was facing the therapist. Set the digital inclinometer as it was on vertical position 90 degree appeared hold then the patient moved his arm into internal rotation or external rotation, take the reading then subtract the reading from 90 . That gave the internal rotation exact range.

Treatment procedures: All participants received conventional physical therapy program. Gentle progressive stretching exercise till the limit of pain was applied for 30 seconds, at the directions of shoulder flexion, external rotation, internal rotation and abduction. Holding each movement for 30 seconds was followed by 15 seconds of relaxation. The patient could do it as home exercise program, each exercise was repeated 3 times per session, the tension was increased every week based on patient's tolerance [19]. Strengthening exercises were started as an isometric program for shoulder flexion, external rotation, internal rotation and abduction then progressed to resist strengthening through the full arc of motion [19]. Shoulder mobilizing exercises to increase range of motion [20] The repetitions were 5 repetitions each type 3 times [15] were the following: Codman/pendulum exercise, shoulder wheel and wall climbing (finger ladder) exercise. Physical agents program treatment [6]: Ultrasound application (pulsed mode, $1 \mathrm{MHz}$ frequency, stroking technique, at $1.5 \mathrm{~W} / \mathrm{cm}^{2}$, for 10mins, and hot packs for 15 minutes applied on shoulder [15] while the head rested on plinth with a pillow. Daily home exercises and self- mobilization using cane to improve internal and external rotation, four types of exercises such as stretching pectorals, finger climbing, cane exercises and pendulum exercise were advised for 5 repetitions. Repetitions of each type four times daily 7 days per week for 4 months as home program [20]

Mobilization with movement (Mulligan) technique was applied for group (C) beside the conventional physical therapy program, the technique was applied according to [21]. The technique is pain free, up to 6 repetitions. The treatment were 3-5 sets of 6-10 repetitions. MWM for shoulder flexion, abduction and elevation Mid-range mobilization in sitting-postero-lateral glides (Technique at Glance). Inferior glide MWM to restore a loss of internal rotation (hand behind back). End-range shoulder elevation MWM in supine posterior and inferior glide. To improve shoulder external rotation apply posterior joint mobilization [22]

Diclofenac phonophoresis was applied for group (B) beside the conventional therapy program, the technique was applied according to [15,23]. Apply the diclophen gel (voltaren gel) on the head of the US and apply it on the axilla of the affected shoulder. Set the parameters as $1 \mathrm{MHz}$ frequency, stroking technique, at $1.5 \mathrm{~W} / \mathrm{cm}^{2}, 10$ minutes [11]. The application of US was adopted as the axilla is the site of the axillary pouch of the capsule, which has been implicated in inflammation and adhesion within shoulder joint that may interfere with the ROM. The axillary pouch is obliterated in many cases of frozen shoulder and this obliteration has been correlated with a decrease in both internal and external rotation. Axillary adhesions can slowly tighten and cause the shoulder joint to lose mobility over time [23].

\section{Data analysis:}

Collected data was statistically analyzed was by using (SPSS, Inc. Chicago, IL, USA) program version 20. Prior to final analysis. Normality test of data using Shapiro-Wilk test was used. This ensures that the data is normally distributed for pain and ROM.

Accordingly, 3 X 2 Mixed MANOVA test was used to compare the tested variables of interest at different measuring periods at three groups. Concerning ordinal variables (hand to neck, hand to scapula and hand to opposite), Wilcoxon Signed Rank tests were used to compare pretreatment versus post-treatment for the all tested variables of interest at three groups. Also, Kruskal-Wallis $\mathrm{H}$-test (nonparametric alternative to the one-way between subject (ANOVA) was used to compare among three groups in different measuring periods. 
Mann-Whitney U-tests were used as post hoc tests if Kruskal-Wallis H-test is significant. With the initial alpha level set at 0.05 .

\section{Results}

There were no statistically significant differences $(p>0.05)$ among groups in all groups concerning physical characteristics: Age, weight, height, and BMI (Table 1).

Regarding subject effect, the descriptive statistics of each of the dependent group are presented in (Table 2). Multiple pairwise comparisons post hoc test revealed that there was a significant difference between Group (A) and Group (C) in pain intensity level $(p=0.001)$. Shoulder ROM (flexion, internal and external rotation) $(p=0.011,0.0001$, $0.0001)$ respectively.

While the result between groups indicated that, there was significant difference between Group
(B) and Group (C) compared with Group (A) in shoulder ROM (internal and external rotation).

There was significant difference between Group (A) and Group (B) in pain intensity level ( $p=$ 0.029 ).

Statistical analysis using 3 X 2 mixed design MANOVA indicated that there were significant effects of the tested group (the first independent variable) on the all tested dependent variables; pain level and ROM of shoulder flexion, abduction, internal and external rotation $(\mathrm{F}=2.81, p=0.008)$. In addition, there were significant effects of the measuring periods (the second independent variable) on the tested dependent variables $(\mathrm{F}=319.716$, $p=0.0001)$. Also, the interaction between the two independent variables was significant, which indicates that the effect of the tested group (first independent variable) on the dependent variables was influenced by the measuring periods (second independent variable) $(\mathrm{F}=5.341, p=0.0001)$ (Table 3$)$.

Table (1): Physical characteristics for the three tested groups.

\begin{tabular}{llllcc}
\hline & Group A & Group B & Group C & F-value & $p$-value \\
\hline Age (years) & $55.85 \pm 5$ & $56.63 \pm 4$ & $55.72 \pm 5$ & 0.107 & 0.899 \\
Body mass (Kg) & $77.42 \pm 6$ & $76.54 \pm 8$ & $71.63 \pm 8$ & 2.065 & 0.143 \\
Height $(\mathrm{cm})$ & $1.65 \pm 0.1$ & $1.64 \pm 0.1$ & $1.66 \pm 0.06$ & 0.133 & 0.876 \\
\hline
\end{tabular}

Table (2): Descriptive statistics of all dependent variables (pain and shoulder range of motion.

\begin{tabular}{|c|c|c|c|c|c|c|}
\hline \multirow{2}{*}{$\begin{array}{l}\text { Dependent } \\
\text { variable }\end{array}$} & \multicolumn{2}{|c|}{ Group A } & \multicolumn{2}{|c|}{ Group B } & \multicolumn{2}{|c|}{ Group C } \\
\hline & Pre & Post & Pre & Post & Pre & Post \\
\hline Pain ROM & $7.27 \pm 1$ & $4.18 \pm 1$ & $6.9 \pm 1$ & $3.18 \pm 0.87$ & $7.5 \pm 0.75$ & $2.62 \pm 0.51$ \\
\hline Flexion & $82.4 \pm 5$ & $145 \pm 19$ & $82.27 \pm 4$ & $152.7 \pm 16$ & $83.5 \pm 7$ & $169.37 \pm 11$ \\
\hline Abduction & $79.09 \pm 6$ & $141.81 \pm 24$ & $80.45 \pm 5$ & $145.54 \pm 24$ & $79.75 \pm 6$ & $167.62 \pm 8$ \\
\hline Internal rotation & $25 \pm 9$ & $39.7 \pm 10$ & $26 \pm 12$ & $43 \pm 17$ & $30 \pm 11$ & $68 \pm 12$ \\
\hline External rotation & $25 \pm 6$ & $45 \pm 13$ & $28 \pm 6$ & $57 \pm 11$ & $32 \pm 6$ & $76 \pm 11$ \\
\hline
\end{tabular}

Table (3): The 3 X 2 mixed design multivariate analysis of variance (MANOVA) for all dependent variables at different measuring periods between all groups.

\begin{tabular}{lll}
\hline Source of variaion & F-value & $p$-value \\
\hline Groups & 2.81 & $0.008^{*}$ \\
Measuring periods & 319.716 & $0.0001^{*}$ \\
Interaction & 5.341 & $0.0001^{*}$ \\
\hline
\end{tabular}

*: Significant at alpha level $<0.05$.

\section{Discussion}

Thirty six patients recruited according to power analysis participated in this study, and were assigned randomly into three groups; all groups received conventional physical therapy program for four weeks Group (A): 14 patients received conventional physical therapy only; while in Group
(B): Diclofenac phonophoresis was added three times per week for 11 patients, and in Group (C): MWM technique was added twice per week for 11 patients.

According to the result of the current study, pain intensity level was decreased within each of the three groups and shoulder ROM was improved. Between groups; pain was decreased and shoulder flexion, internal rotation and external rotation was improved in MWM group in contrast to the conventional treatment. Internal and external rotation were improved favoring MWM in comparison to phonophoresis group.

The therapeutic exercises and mobilization therapy strongly recommended for reducing pain 
and improving ROM in stages 2 and 3 adhesive capsulitis as recommended by systematic review conducted by Kinser and Colby [19]. The results of the current study are in agreement with Griggs and Green [24] who investigated the effect of a specific four-direction shoulder-stretching exercise program which revealed improvement in shoulder pain at rest and activity. It was accompanied with increasing shoulder forward elevation, active external and internal rotation, and shoulder abduction.

Shrivastave et al., [25] compared mulligan's versus maitland's mobilization technique in adhesive capsulitis of shoulder joint. A prospective randomized double blind study was performed with 20 patients in each treatment arm. It showed that both the treatment techniques maitland and mulligan improved the pain VAS score, but mulligan mobilization technique is better than maitland in terms of improvement in the range of extension.

The results of the current study are in agreement with Barua et al., [16] who investigated the effect of phonophoresis on shoulder adhesive capsulitis, revealed that group (B) which treated with phonophoresis and exercises was improved at all sorts of ROM of the affected shoulder than group (A) which treated with the same exercises without phonophoresis.

In contrast, the meta analysis done by Green et al. [26] found ultrasound alone with no exercises has no additional benefit in pain reduction in adhesive capsulitis patients.

\section{Conclusion:}

The study concluded that both diaclofenac phonophoresis combined with conventional physical therapy program and MWM had decreased the patient's pain severity and increased the shoulder ROM. But, MWM technique combined with conventional physical therapy program had the superiority in improving the shoulder ROM.

\section{References}

1- LEWIS J.: Frozen shoulder contracture syndromeAetiology, diagnosis and management. Manual therapy, 20 (1): 2-9, 2015.

2- ROBINSON C.N., SEAH K.T., CHEE Y.H., HINDLE P. and MURRAY I.R.: Frozen shoulder. The journal of bone and joint surgery British volume, 94 (1): 1-9. Epub 2012/01/06, 2012.

3- STAPLES M.P., FORBES A., GREEN S. and BUCHBINDER R.: Shoulder-specific disability measures showed acceptable construct validity and responsiveness. Journal of clinical epidemiology, 63 (2): 163-70, 2010.

4- AYDENIZ A., GURSOY S. and GUNEY E.: Which musculoskeletal complications are most frequently seen in type 2 diabetes mellitus? Journal of International Medical Research, 36 (3): 505-11, 2008.

5- SCHULTHEIS A., REICHWEIN F. and NEBELUNG W. Frozen shoulder. Diagnosis and therapy. Orthopade, 37 (11): 1065-72, 2008.

6- MARTIN S.D.: ThornhillnTS. Shoulder pain. Firestein GS, Budd RC, Harris ED et al. Kelley's Textbook of Rheumatology. 8th ed. Elsevier: Saunders, 607-8, 2009.

7- DAHAN T.H., FORTIN L., PELLETIER M.I.C.H.E.L., PETIT M.I.C.H.E.L., VADEBONCOEUR R.O.G.E.R. and SUISSA S.A.M.Y.: Double blind randomized clinical trial examining the efficacy of bupivacaine suprascapular nerve blocks in frozen shoulder. The Journal of rheumatology, 27 (6): 1464-9, 2000.

8- TEYS P., BISSET L. and VICENZINO B.: The initial effects of a Mulligan's mobilization with movement technique on range of movement and pressure pain threshold in pain-limited shoulders. Manual therapy, 13 (1): 37 42, 2008.

9- CLELAND J. and DURALL C.J.: Physical therapy for adhesive capsulitis: Systematic review. Physiotherapy, 88 (8): 450-7, 2002.

10- DODENHOFF R.M., LEVY O., WILSON A. and COPELAND S.A.: Manipulation under anesthesia for primary frozen shoulder: Effect on early recovery and return to activity. Journal of shoulder and elbow surgery, 9 (1): 236, 2000.

11- DAVID C.W. and KURTIS M.H.: Physical Agent Modalities. In: Braddom RL (editor). Physical Medicine \& Rehabilitation. 3rd ed. Elsevier: Saunders; 464-72, 2007.

12- ROBERTSON V.W. A., LOW J. and REED A.: Electrotherapy Explained Principles and Practice. 4 th ed. Elsevier: Butterworth Heinemann; 251-97, 2009.

13- GUPTA A.K., CHALMERS P.N., RAHMAN Z., BRUCE B., HARRIS J.D., McCORMICK F. and NICHOLSON G.P.: Reverse total shoulder arthroplasty in patients of varying body mass index. Journal of Shoulder and Elbow Surgery, 23 (1): 35-42, 2014.

14- ARSHAD H.S., SHAH I.H. and NASIR R.H.: Comparison of mulligan mobilization with movement and end-range mobilization following maitland techniques in patients with frozen shoulder in improving range of motion. Pain, $1,2,2015$.

15- JAIN T.K. and SHARMA N.K.: The effectiveness of physiotherapeutic interventions in treatment of frozen shoulder/adhesive capsulitis: A systematic review. Journal of back and musculoskeletal rehabilitation, 27 (3): 247 73, 2014.

16- BARUA S.K., RAHMAN S., CHAKRABARTI P.K. and ALAM Z.: Role of phonophoresis in management of adhesive capsulitis (Frozen Shoulder), Chattagram MaaO-Shishu Hospital Medical collage journal, 13 (2): 21 7, 2014.

17- ADEL S.M., ELAZM S.N.A., ABDEL-RAOOF N.A. \& AHMED K.T.: Shock Wave versus Phonophoresis in Treatment of Diabetic Frozen Shoulder. in-Chief Message, 2 (6): 148-56, 2013.

18- CHILDS J.D., PIVA S.R. and FRITZ J.M.: Responsiveness of the numeric pain rating scale in patients with low back pain. Spine, 1; 30 (11): 1331-4, 2005. 
19- KISNER C. and COLBY L.A.: Therapeutic exercise foundations and techniques. 4 th ed. Jaypee, 43-9, 282, 2012.

20- TANAKA K., SAURA R., TAKAHASHI N., HIURA Y. and HASHIMOTO R.: Joint mobilization versus selfexercises for limited glenohumeral joint mobility: Randomized controlled study of management of rehabilitation. Clin. Rheumatol., 29: 1439-44, 2010.

21- HING W., HALL T., RIVETT D.A., VICENZINO B. and MULLIGAN B.: The mulligan concept of manual therapy: Textbook of techniques. Elsevier Health Sciences, 2015.

22- JOHNSON A.J., GODGES J.J., ZIMMERMAN G.J. and OUNANIAN L.L.: The effect of anterior versus posterior glide joint mobilization on external rotation range of motion in patients with shoulder adhesive capsulitis. journal of orthopaedic \& sports physical therapy, 37 (3): 88-99, 2007.
23- ELHAFEZ H.M. and ELHAFEZ S.M.: Axillary Ultrasound and Laser Combined With Postisometric Facilitation in Treatment of Shoulder Adhesive Capsulitis: A Randomized Clinical Trial. Journal of manipulative and physiological therapeutics, 39 (5): 330-8, 2016.

24- GRIGGS S.M., AHN A. and GREEN A.: Idiopathic adhesive capsulitis: A prospective functional outcome study of nonoperative treatment. JBJS, 82 (10): 13981406, 2000.

25- SHRIVASTAVA A., SHYAM A.K., SABNIS S. and SANCHETI P.: Randomised controlled study of Mulligan's vs. Maitland's mobilization technique in adhesive capsulitis of shoulder joint. Indian journal of physiotherapy and occupational therapy-An international Journal, 5 (4): 125, 2011.

26- GREEN S., BUCHBINDER R. and HETRICK S.E.: Physiotherapy interventions for shoulder pain. Cochrane database of systematic reviews, (2), 2003.

\title{
تآثير التليين مع الحركة مقابل إدخال ديكلوفيناك الموتئ

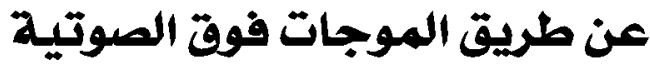 فى علاج إلتهاب المحفظة الإلتصاقى المفصل الكوقي المتف
}

\author{
الهدف من البحت: مقارنة تآثير التليين مع الحركة مقابل إنخال ديكوفيناك عن طريق الموجات فوق الصوتية فى علاج إلتهاب المحفظة \\ الإلتصاقى لمفصل الكتف.
}

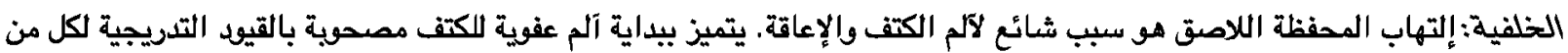

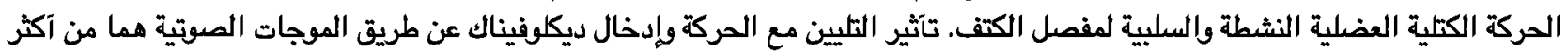

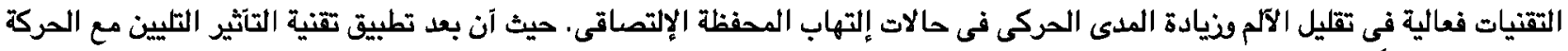
يقل الآلم، وآيضاً الموجات فوق الصوتية تقلل الآلم والخشونة وبإضافة الآدوية المضادة للإلتهاب الغير ستيرودية يصدث راحة إضافية من الآلم بمفصل الكتف.

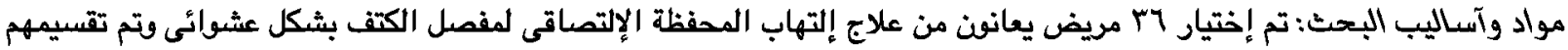

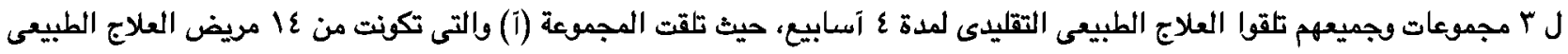

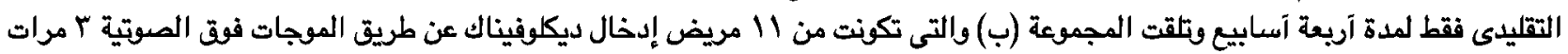

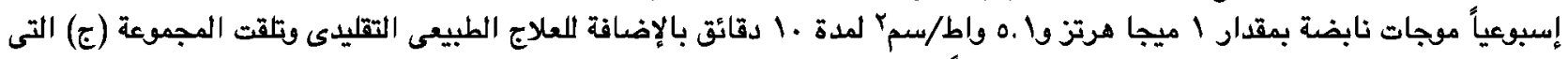

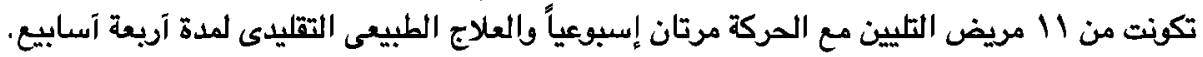

القياسـات: هستوى شدة الآلم وقد تم قياسه بواسطة مقياس الآلم الرقمى، والمدى الحركى بإستخدام جهاز قياس المدى الحركى الرقهى

سوندر.

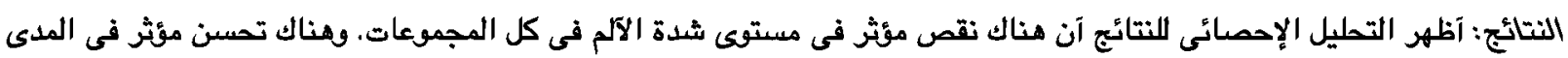

الحركى لمفصل الكتف لكل المجموعات الكن آفضل نسب اللتسمن كانت في المجموعة (ع).

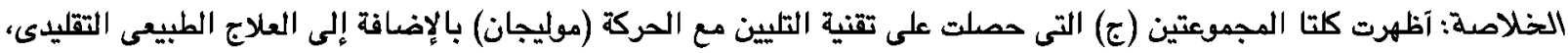

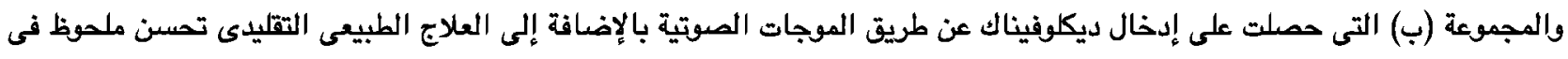

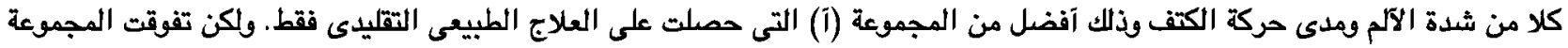
(ع) فى تصسن مدى حركة الكتف. 